\title{
Commentary: Ascending to the summit of robotic hybrid revascularization
}

\author{
Lawrence M. Wei, MD, Harold G. Roberts, MD, and Vinay Badhwar, MD
}

\author{
From the Department of Cardiovascular and Thoracic Surgery, West Virginia University, Morgantown, WVa. \\ Disclosures: Authors have nothing to disclose with regard to commercial support. \\ Received for publication Sept 12, 2018; accepted for publication Sept 13, 2018; available ahead of print Nov 3 , \\ 2018. \\ Address for reprints: Vinay Badhwar, MD, Department of Cardiovascular and Thoracic Surgery, West Virginia \\ University, 1 Medical Center Dr, Morgantown, WV 26506 (E-mail: vinay.badhwar@wvumedicine.org). \\ J Thorac Cardiovasc Surg 2019;157:1839-40 \\ $0022-5223 / \$ 36.00$ \\ Copyright (C) 2018 Published by Elsevier Inc. on behalf of The American Association for Thoracic Surgery \\ https://doi.org/10.1016/j.jtcvs.2018.09.042
}

Kitahara and colleagues ${ }^{1}$ present midterm outcomes of a single-center series of 57 patients who underwent advanced hybrid coronary revascularization (HCR) that combined robot-assisted beating-heart multi-vessel totally endoscopic coronary artery bypass (TECAB) and percutaneous coronary intervention (PCI). Bilateral internal thoracic artery (BITA) grafting was performed in $87.7 \%$ of patients and no patient required conversion to open thoracotomy. Graft patency was $>95 \%$. Three-year survival was $92.8 \%$ and freedom from major adverse cardiac events was $80.2 \%$. These impressive results are a testament to the skill and dedication of Kitahara and colleagues ${ }^{1}$ for spearheading the development of robotic TECAB. To perform the procedures in this series, they were required to master special skills of conduit harvesting and apply enhancing technology, including the use of anastomotic connectors. Although this skill set is impressive and laudable, devoting the time and effort to duplicate these efforts may challenge most surgeons and programs.

Coronary artery bypass grafting (CABG) with a left internal thoracic artery (LITA) has long-established survival benefits, especially in certain patient subgroups, but multivessel PCI remains commonly performed due to patient or physician preference for its lesser invasiveness. Advanced HCR capitalizes on the benefits of a LITA graft to the left anterior descending while reducing morbidity through a nonsternotomy minimally invasive approach, whereas lesions not of the left anterior descending are addressed by PCI. Use of the robot further reduces incision size and rib spreading. Moreover, given the growing body of literature supporting routine use of BITA grafts, ${ }^{2}$ the investigators are to be commended for their routine use of BITA grafts in this series.

Although the feasibility of HCR to treat multivessel disease as part of a comprehensive program has been demonstrated, use remains low. ${ }^{3,4}$ In the United States, HCR was performed in only $0.48 \%$ of isolated CABG cases. ${ }^{5}$ However, recent interest in the interdisciplinary HCR approach to multivessel coronary artery disease has led to an ongoing National Heart, Lung, and Blood Institute-sponsored

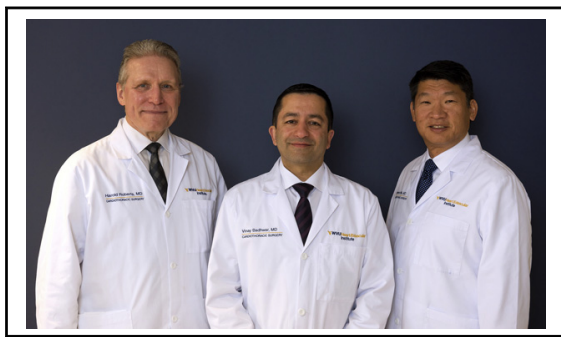

Harold G. Roberts, Vinay Badhwar, MD, and Lawrence M. Wei, MD

\section{Central Message}

Totally endoscopic robotic assisted coronary revascularization remains a dedicated team sport for which all surgeons and programs may not quite be ready.

See Article page 1829.

multicenter randomized trial of HCR versus PCI (https:// clinicaltrials.gov/ct2/show/NCT03089398). If the data support HCR, it would be a strong impetus to wider adoption of the HCR approach as an alternative to multivessel PCI.

The current study ${ }^{1}$ demonstrates an approach to the surgical component of HCR and this represents the state of the art of robot-assisted coronary revascularization. However, most surgeons currently do not perform minimally invasive direct CABG (MIDCAB) with any appreciable frequency. It thus may be unrealistic to expect the adoption of the more demanding, costly, and timeconsuming TECAB technique. In our practice, we regularly perform robot-assisted LITA harvesting and MIDCAB with hand-sewn anastomoses, and a growing proportion of these procedures comprise the surgical component of our HCR program. Utilizing this approach may be more costeffective than TECAB. It avoids the cost of anastomotic connectors and it permits operative efficiencies to enable the performance of more than 1 robotic MIDCAB operation per day in an operating room.

The outstanding work demonstrated by Kitahara and colleagues ${ }^{1}$ represents the laudable culmination of a multiyear ascent to the summit of robotic revascularization by a dedicated team of operators. Several surgeons have reached the base camp of reproducible robotic ITA harvest and direct-vision MIDCAB. However, the arduous journey to the TECAB summit is likely too long and the air too thin for most surgeons and their patients to currently reach safely. 


\section{References}

1. Kitahara H, Hirai T, McCrorey M, Patel B, Nisivaco S, Nathan S, et al. Hybrid coronary revascularization: midterm outcomes of robotic multivessel bypass and percutaneous interventions. J Thorac Cardiovasc Surg. 2019;157:1829-36.e1.

2. Buttar SN, Yan TD, Taggart DP, Tian DH. Long-term and short-term outcomes of using bilateral internal mammary artery grafting versus left internal mammary artery grafting: a meta-analysis. Heart. 2017;103:1419-26.

3. Tajstra M, Hrapkowicz T, Hawranek M, Filipiak K, Gierlotka M, Zembala M, et al. Hybrid coronary revascularization in selected patients with multivessel disease: 5-year clinical outcomes of the prospective randomized pilot study JACC Cardiovasc Interv. 2018;11:847-52.

4. Puskas JD, Halkos ME, DeRose JJ, Bagiella E, Miller MA, Overbey J, et al Hybrid coronary revascularization for the treatment of multivessel coronary artery disease: a multicenter observational study. J Am Coll Cardiol. 2016;68:356-65.

5. Harskamp RE, Brennan JM, Xian Y, Halkos ME, Puskas JD, Thourani VH, et al Practice patterns and clinical outcomes after hybrid coronary revascularization in the United States: an analysis from the society of thoracic surgeons adult cardiac database. Circulation. 2014;130:872-9. 